\title{
Hospitals Surfaces and Sites as a Reservoir for Pathogenic Bacteria That Play a Role in Transmission of Infectious Diseases
}

\author{
Maina Susan Muthoni \\ Department of Medical Microbiology, School of Biomedical Sciences, Jomo Kenyatta University of Agriculture and Technology (JKUAT), \\ Nairobi, Kenya
}

Email address:

msonimukiri@gmail.com

\section{To cite this article:}

Maina Susan Muthoni. Hospitals Surfaces and Sites as a Reservoir for Pathogenic Bacteria That Play a Role in Transmission of Infectious Diseases. Journal of Health and Environmental Research. Vol. 7, No. 3, 2021, pp. 139-144. doi: 10.11648/j.jher.20210703.14

Received: June 18, 2021; Accepted: July 6, 2021; Published: July 24, 2021

\begin{abstract}
The key to success of healthcare quality is the control of hospital environment. Challenge of infection prevention and epidemiology practice continues to be an increasing emergence and spread of pathogenic bacteria is of great concern. The study is about the prevalence and isolation of bacteria from hospital surfaces environment in Kenya. About 246 samples of the two hospitals was obtained using sterile cotton swabs from random sampling of hospital different surfaces, drainages, hands of healthcare givers and hospital waste dump site among others. The samples were aseptically collected, transported and processed following standard procedures. Bacteria were isolated and identified using various biochemical tests and confirmed using API 20E. Door handle surfaces had the highest percentage of isolated bacteria (13\%) while the least was cupboard surfaces $(3 \%)$ in both hospitals. Kenyatta National Hospital (KNH) had the most isolated bacteria as compared to Kikuyu Mission Hospital (KMH) in most swabbed surfaces; the difference however was not significant. Various bacteria were isolated where the most abundant bacteria in both hospitals was Providencia species, while the least was Enterobacter species. There is therefore, high bacteria contamination of objects of hospitals frequently touched sites and surfaces act as a source of infectious diseases as they harbor potential pathogens.
\end{abstract}

Keywords: Surfaces, Hospital, Contamination, Bacteria

\section{Background}

Nosocomial infection or hospital acquired infection; is an infection acquired in hospital by a patient who was admitted for a reason other than that infection [1]. Diseases caused by nosocomial infections that are acquired from the hospital and healthcare environment within few days of admission and are responsible for nosocomial infections [2]. A closed community like a hospital, is therefore not surprising that certain microorganisms become predominant and cause diseases. The pathogens can be expelled from an infected or colonized patient either through direct contact, aerosols droplets or feaces to the environmental surfaces [2]. Healthcare workers and patients can be contracted by these pathogens. Improper handling and management of the hospital surfaces waste and general environment is also an important cause of nosocomial infections [1].
Healthcare centers environmental surfaces act as reservoir for bacteria and can as well serve as vectors of the bacteria [3]. Environmental conditions, may remain infectious on the surfaces for weeks after the contamination event and the transmission of microorganisms. Environmental surfaces to patients is largely via hand contact with the surfaces [4]. Otter [5] reported that surfaces can play important role in the epidemic and endemic transmission of the major pathogens linked to healthcare associated infections. This pose a problem of enormous magnitude globally; hospital localities have proven favorable in transmission of infection due to existing suitable pathogens-host environment relationship [6]. Formation of biofilms involves micro-organisms universally attaching to surfaces and produce extracellular polysaccharides. A serious problem for public health is posed by biofilms because of the increased resistance of biofilm associated organisms to antimicrobial agents and the potential for these 
organisms to cause infections in patients with indwelling medical devices [7]. They have great significance for public health, because biofilm associated microorganisms exhibit dramatically decreased susceptibility to antimicrobial agents. Bloodstream infection and urinary tract infections are associated with in dwelling medical device and therefore, the most effective strategy for treating these infections may be removal of the biofilm contaminated devices [8].

\section{Materials and Methods}

\subsection{Study Site and Sampling}

This research study was carried out two various hospitals within the Nairobi City and surrounding county, Kiambu. The hospitals were conveniently classified based on their ownership (public or private) and the diversity of their facilities and services rendered. The research study site included Kenyatta National Hospital (KNH) situated in Nairobi County and Presbyterian Church of East Africa (PCEA) Kikuyu Mission Hospital (KMH), Kiambu County. Kenyatta National Hospital was chosen due to the fact that it's the largest public teaching and referral hospital in Kenya, with over 1800 beds, over 6000 staff, 50 wards and 24 theatres. It records the biggest human traffic in a Kenyan health establishment and hence there is a need for proper hospital waste management to minimize the risks involved. The PCEA Kikuyu Mission Hospital (KMH) represented a private hospital serving Kiambu County and surrounding Counties, with about 218 beds, around 346 staff, 5 wards, 4 theatres. $\mathrm{KMH}$ was also selected to represent private referral hospital. High population density in the study sites assures that a large number of people are exposed to toxic level of hospital waste. These hospitals were selected for study to detect any form of surface contamination in the hospitals. A cross-sectional study design utilizing a systematic random sampling technique was adopted. All members of the study population had an equal and independent chance of being selected.

Simple random sampling method was used to collect samples from various surfaces in each hospital from different departments namely surgery, general wards, intensive care units, and operation theatre, Surface swab specimens were collected from predefined surfaces such as operating tables, door handles. Medical devices, floor, sinks, nurses hands elevator buttons among others, by using cotton swabs moistened with sterile normal saline water according to ISO/DIS 14698 (ISO, 2003). The choice of sampling point was made in consultation with the heads of departments and targeted the most representative locations in each department. At least twenty-five samples were collected per week over a period of ten weeks for each hospital guided by the number of samples. The environmental samples collected for this study was 246. The second day of the week were the day of collection for KMH while the fourth day of the week was for $\mathrm{KNH}$. The collection was made in the early hours of the morning and transported in a cooler kept at $5 \pm 3^{\circ} \mathrm{C}$ to be analyzed at the institute of primate research laboratories,
Kenya. After delivery of samples to the laboratory, each swab was immersed in liquid nutrient broth and incubated for $37 \pm 1^{\circ} \mathrm{C}$. Growth was noted, and the swabs were further sub cultured in MacConkey agar and the salt agar, then they were incubated at $37^{\circ} \mathrm{C}$ for 24 hours and the distinct colonies were isolated and purified by sub culturing in fresh media and incubating at $37 \pm 1^{\circ} \mathrm{C}$ for 18 -24 hours to obtain pure culture isolates. The cultural, morphological, biochemical and physiological characterization of the bacterial isolates were determined by classical biochemical techniques and the API (BioMerieux, France).

\subsection{Statistical Analysis}

In this study, tables, graphs and pie charts were used to present the data, which was entered into a Microsoft $\AA$ Excel spread sheet, exported and analyzed using the statistical package for the social science (SPSS) package version 13.0 (IBM, Chicago).

\section{Results and Discussion}

From the study, a total of 492 samples distributed in each of the surfaces. Of these samples 423 (86) showed positive cultures and 471 isolates were identified. The isolation of bacteria was highest on door handles $(13 \%)$ followed by nurse's hands surfaces (11\%), while the least was cupboard surfaces $(3 \%)$ followed by bed rails (4\%). KNH (52\%) had more bacteria isolated from its surfaces as compared to $\mathrm{KMH}$ (48\%) (Figure 1), though the difference was not significantly different. Bacteria isolated from the $\mathrm{KNH} \mathrm{282,} \mathrm{(59.8)} \mathrm{is} \mathrm{more}$ than in the KMH 189, (40.2). This is similar to studies done [26], found government hospitals having more bacteria as compared to private hospitals. Improper or insufficient treatment of the wastes before disposal is a reflection of the practices in these establishments. Significant difference in the number bacteria isolates of bacteria in various sites and surfaces in both hospitals was recorded; several factors may contribute to this as in agreement with the previous study by other scholars where it was shown that the difference in quality of the ventilation system, in cleaning procedures and traffic in these areas [9].

Providencia species was the most abundant bacteria, while the least was Enterobacter species.\%) (Table 1).

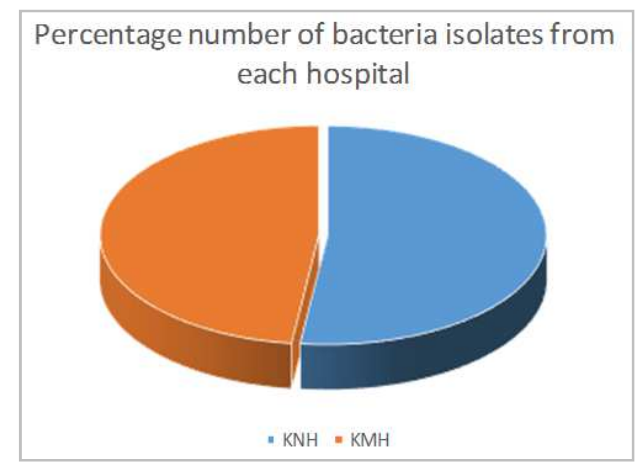

Figure 1. To show the proportion in percentage of bacterial isolates from each hospital. 
In sinks, Pseudomonas species were most abundant (20.4\%) followed by operation table $(18 \%)$. In operation table $(27 \%)$ Klebsiella species were mostly found there, then door handles $(20 \%)$. E. coli was isolated in nurses' hands surface (NHS) at (23\%), followed by nurses' staff table (NST) at 20\%. Proteus species were mostly found in stretchers and elevator buttons in $26 \%$ in both, and Enterobacter cloaca was most prevalent in nurses' hands surfaces at 50\%, in door handles at 14\% Providencia species were mostly recorded, while Serratia species were frequent in waste water samples and door surfaces at $23 \%$. Other Gram negative isolates were found in waste water and door surfaces etc. Staphylococcus aureus was abundantly found in nurses' hands surface in about $22 \%$. Coagulase negative Staphylococcus was most abundant in elevator buttons (40\%) and door handles in $26 \%$ occurrence (Table 1).

Table 1. Prevalence of bacteria in their various locations in the hospitals.

\begin{tabular}{|c|c|c|c|c|c|c|c|c|c|c|c|c|c|c|c|}
\hline SS & HOSP & SZ & $P D$ & $K B$ & $E C$ & $P T$ & $E N C$ & $P S$ & $S T$ & OGM & $S A$ & CONS & $\begin{array}{l}\text { Total number } \\
\text { of bacteria }\end{array}$ & Overall & $\%$ \\
\hline \multirow[t]{2}{*}{ NHS } & $\mathrm{KNH}$ & 19 & 0 & 0 & 10 & 0 & 2 & 3 & 0 & 2 & 10 & 3 & 30 & 50 & 11 \\
\hline & $\mathrm{KMH}$ & 19 & 0 & 0 & 4 & 0 & 4 & 2 & 0 & 0 & 9 & 1 & 20 & & \\
\hline NST & $\mathrm{KMH}$ & 18 & 0 & 1 & 4 & 1 & 0 & 3 & 0 & 3 & 4 & 1 & 17 & & \\
\hline \multirow[t]{2}{*}{$\mathrm{DH}$} & $\mathrm{KNH}$ & 19 & 0 & 5 & 4 & 0 & 0 & 6 & 0 & 0 & 8 & 4 & 27 & 59 & 13 \\
\hline & $\mathrm{KMH}$ & 19 & 0 & 1 & 6 & 0 & 2 & 8 & 0 & 1 & 7 & 7 & 32 & & \\
\hline TS & $\mathrm{KMH}$ & 19 & 5 & 0 & 0 & 0 & 0 & 3 & 2 & 2 & 4 & 0 & 16 & & \\
\hline \multirow[t]{2}{*}{ OT } & $\mathrm{KNH}$ & 18 & 5 & 4 & 7 & 0 & 0 & 6 & 1 & 1 & 2 & 0 & 26 & 44 & 9 \\
\hline & $\mathrm{KMH}$ & 19 & 3 & 4 & 1 & 2 & 0 & 2 & 0 & 1 & 4 & 1 & 18 & & \\
\hline \multirow[t]{2}{*}{ Sink } & $\mathrm{KNH}$ & 19 & 6 & 1 & 0 & 2 & 0 & 7 & 1 & 4 & 0 & 0 & 21 & 36 & 7 \\
\hline & $\mathrm{KMH}$ & 19 & 3 & 1 & 0 & 1 & 0 & 4 & 4 & 2 & 0 & 0 & 15 & & \\
\hline \multirow{2}{*}{ Stretcher } & $\mathrm{KNH}$ & 19 & 0 & 0 & 5 & 3 & 1 & 10 & 0 & 1 & 1 & 2 & 23 & 37 & 8 \\
\hline & $\mathrm{KMH}$ & 19 & 0 & 0 & 4 & 2 & 0 & 3 & 1 & 2 & 2 & 0 & 14 & & \\
\hline floor surface & $\mathrm{KNH}$ & 19 & 5 & 0 & 0 & 1 & 0 & 7 & 1 & 1 & 2 & 1 & 18 & 28 & 6 \\
\hline \multirow[t]{2}{*}{ EB } & $\mathrm{KNH}$ & 19 & 3 & 0 & 4 & 2 & 1 & 0 & 1 & 0 & 0 & 2 & 14 & 26 & 7 \\
\hline & $\mathrm{KMH}$ & 19 & 1 & 0 & 1 & 3 & 4 & 1 & 1 & 0 & 0 & 1 & 12 & & \\
\hline \multirow[t]{2}{*}{ WW } & $\mathrm{KNH}$ & 19 & 2 & 1 & 0 & 2 & 0 & 4 & 6 & 5 & 0 & 0 & 20 & 35 & 7 \\
\hline & $\mathrm{KMH}$ & 19 & 4 & 3 & 0 & 2 & 0 & 2 & 1 & 3 & 0 & 0 & 15 & & \\
\hline \multirow[t]{2}{*}{ DS } & $\mathrm{KNH}$ & 19 & 2 & 1 & 0 & 0 & 0 & 4 & 4 & 3 & 0 & 0 & 14 & 26 & 5 \\
\hline & $\mathrm{KMH}$ & 19 & 0 & 3 & 0 & 0 & 0 & 1 & 3 & 5 & 0 & 2 & 12 & & \\
\hline \multirow[t]{2}{*}{ BR } & $\mathrm{KNH}$ & 19 & 0 & 3 & 1 & 1 & 0 & 1 & 2 & 1 & 5 & 0 & 14 & 18 & 4 \\
\hline & $\mathrm{KMH}$ & 19 & 0 & 0 & 0 & 0 & 1 & 1 & 0 & 0 & 1 & 1 & 4 & & \\
\hline \multirow[t]{2}{*}{$\mathrm{CB}$} & $\mathrm{KNH}$ & 19 & 0 & 0 & 1 & 0 & 0 & 3 & 1 & 2 & 2 & 0 & 9 & 16 & 3 \\
\hline & $\mathrm{KMH}$ & 19 & 0 & 0 & 1 & 0 & 0 & 0 & 0 & 0 & 5 & 1 & 7 & & \\
\hline Total & & 492 & 44 & 30 & 61 & 19 & 12 & 99 & 31 & 45 & 87 & 43 & 471 & 471 & 100 \\
\hline
\end{tabular}

Key- SS-sample source, SZ-sample size, PD-Pseudomonas sp, KB-Klebsiella sp, EC-E. coli, PT-Proteus sp, ENC-Enterobacter cloaca, PS-Providentia sp, ST-Serratia sp, OGN-other Gram negatives, SA Staphylococcus aureus CONS-coagulase negative Staphylococcus-NHS-nurse's hands surface, NSTnurses/staff table, DH-door handle, TS-table surfaces, OT- operation table, EB- elevator button, WW- waste water, DS- Device surfaces, BR- beddings/ bedrails, CB- cupboard surfaces. Most bacteria were isolated on nurse's hands surfaces, while the least was found cupboard surfaces. Providentia sp were the most abundant, while Enterobacter cloaca was the least detected.

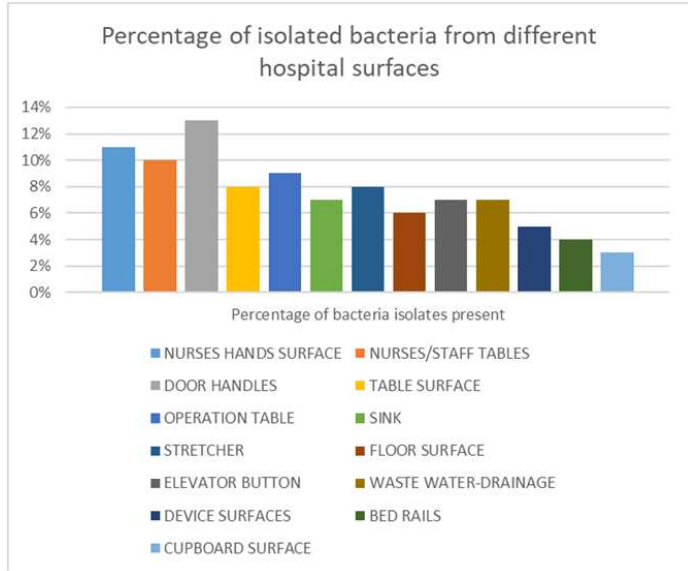

Figure 2. Distribution of percentage of bacteria in different sites and surfaces.
On door handles (13\%) the isolation of bacteria was highest followed by nurse's hands surfaces $(11 \%)$, while the least was cupboard surfaces $(3 \%)$ followed by bed rails $(4 \%)$ (Figure 2). In the current study nurse's/doctors hands and nurses' staff table were colonized by Staphylococcus and was the second most frequently isolated bacterium (19\%). An isolation rate of $13 \%$ was previously recorded in previous reports [10], there was high prevalence of the $S$. aureus isolated from hand swabs and door handles. Inadequate hand hygiene could be one of the attributing factors of the distribution of the pathogen in the hospital environmental surfaces as reported earlier [11]. Prevalence rate of $S$. aureus was recorded as low on beddings and bed rails; this study is not in agreement with $100 \%$ prevalence on bedrail as reported in previous reports [4]. Furthermore, 26\% of $S$. aureus reported on door handle in other reports, [10] is more compared to the prevalence rate of the $S$. aureus on door 
knob/door handle of $17 \%$ from these hospitals in the current study. Diseases such as post-operative infections, urinary tract infections, skin diseases, respiratory infections and food poisoning have been incrimated to have been caused by Staphylococcus sp [13]. Coagulase negative Staphylococcus species (9\%) were mostly found in elevator buttons and other surfaces, this could be due to the fact that they are touched repeatedly by ungloved hands by multiple individuals who will later go on to contact patients colonized by bacteria that were not pathologic.

Prevalence rate of bacteria in door knobs and handles was found to be $16 \% E$. coli. This confirms the early report [14], from some parts of Abuja metropolis that the contamination of door knob/door handle can be as a result of poor hand hygiene after using the toilet. Previous studies have reported the importance of frequent and adequate hand washing to reduce rates of hospital acquired infections $[15,16]$. Failure to washing hands regularly would lead to acquire bacteria pathogens that are responsible of nosocomial infections and can survive on dry surfaces for several weeks [17]. Bacterial isolates are capable of surviving on hands of health care workers for at least several minutes following contamination, hence the necessity of a hand washing facility at most points in a health care institution as reported in previous studies [18]

Waste water drainages, sinks and floors and had the highest number of Pseudomonas species with a prevalence rate of $9 \%$. Prevalence rate of $9.3 \%$ that was similar was reported by [19] in Andhra Pradesh, India. Higher prevalence rate of $32.1 \%$ and $20.3 \%$ was reported by [20] in Gujarat, India respectively and in comparative. The varied prevalence of $P$. aeruginosa in different places may be attributed to the type of swab received for examination, type of hospitals and geographical positions [21]. An opportunistic pathogen for humans such as Pseudomonas sp to a broad spectrum of disease such as urinary, burn, respiratory infections and septicemia [19]. Isolation of Pseudomonas species from the sinks is similar with report of [22], who researched that sinks were the most common place in hospital environment for growth of Pseudomonas species, and the most common article of contact by the people. Among other places, Pseudomonas species thrived on moist surfaces [23], it is therefore and not surprising that the report gave high Pseudomonas aeruginosa isolates since people with wet hands (water or sweat) could easily come into contact with it. The prevalence rate of Pseudomonas species on operation table of the hospitals in the current study hospital was still higher (18\%) than a work reported previously [19] that $9.6 \%$ of the pathogen was isolated from operation table in a hospital in India. The presence of this bacteria on operation table can contaminate open wounds of the patients in course of the operation [23]. The current study shows that Serratia marcescens were found mostly in Intensive Care Unit (ICU) and in samples taken from sinks, door surfaces and waste in ICU and this was confirmed by research done previously [24] it accounts for only $1-2 \%$ of the nosocomial infections and caused by instrumentation.

A significant number of bacteria was found on floor surfaces and especially Providencia species especially in the operating suite. Staphylococcus aureus and coagulasenegative Staphylococci species was the major species contaminating floors and other surfaces in the operating rooms. Among the factors that may contribute to this was the difference in quality of the ventilation system; the difference in cleaning procedures and the difference in traffic in these areas. Major contributing factor to be the difference in cleaning procedures should be considered. Based on researchers' observations, it is recommendable that, there should be regular use of disinfectant in cleaning the operating room floor after every operation. The use of disinfectant on cleaning the floors [25] reported a significant reduction in floor bacteria with the use of a germicidal detergent. It was also reported that the floors in the inner zones of the operating suite cleaned with disinfectant showed low level of bacterial contamination. In the current study, Staphylococcus aureus was found on a pillow (beddings and bed rails category) in one instance. Since operating theatres surfaces were cleaned daily with disinfectant, it was not found holding any contamination.

Surface swabs and wastes collected in $\mathrm{KNH}$ and $\mathrm{KMH}$ hospitals identified most Gram negative bacteria using API$20 \mathrm{E}$ probably, due to the nature of the organism; viable but non-cultivable. Effect of possible pre-treatment given to hospital sites and surfaces was also questionable [26]. It was reported that the variety of pathogenic bacteria were found in sewage sludge, however, Shigella species were not detected in their study probably due to low sensitivity of enrichment procedure and high temperature which decreased its survival in their study. Gram negative bacteria species for example, Pantoea sp. was also isolated (12 isolates) in this study. Previous studies have reported the association of this germ with nosocomial infections [27].

Bacterial contamination in the various departments of the selected hospitals is a serious problem. It was significant because the contaminations were identified in some areas that should be clean like the sterilization and operation room and should contain a minimal number of microbes at all times for the safety of the patients and the health workers. The levels of contamination observed in this study carry a high risk for the development of nosocomial infections. These observations justify need to infection control effort in our hospitals.

\section{Conclusion}

Bacteria contamination in the various surfaces of the selected hospitals is a threat, in some areas that should be sterile such as operation room. The above mentioned areas should be kept clean and should contain a minimal number of microbes at all times for the safety of the patients and the health workers. Levels of contamination observed in this study could lead to high risk of nosocomial infections. The above observations justify that there is need for more attention to be paid to infection control efforts in our 
hospitals. Presence of high number of microorganisms in the hospital sites and surfaces and disposed wastes is another great threat to public health implication most especially due to high resistance to commonly used antibiotics in our hospitals. It is important and urgent to assess and strengthen infection prevention practices and hand hygiene guidelines. Thorough Surface cleaning and disinfection should be thoroughly followed and adhered to in managing outbreaks due to these emerging pathogens is the recommendation in this study.

\section{Availability of Data}

All the relevant data generated and analyzed during this study are included in this manuscript.

\section{References}

[1] Madhukumar, S. \& Ramesh, G. (2012). Study about Awareness and Practices about Health Care Wastes Management among Hospital Staff in a Medical College Hospital, Bangalore. International Journal of Basic Medical Science, 3 (1), 7-11.

[2] Nkonge, N. A, Mayabi, O. A, \& Kithinji, J. (2012). Knowledge, attitude and practice of health-care waste management and associated health risks in the two teaching and referral hospitals in Kenya. Journal Community Health: 37 (60), $1172-7$.

[3] Bakalli M. E. L, Hamid K, Kari K. E, Zouhdi M, Mzibri M. E. L (2015). Characterization of bacterial strains and their resistance status in hospital environment, Journal of Tropical diseases 4: 180. DOI 10.4172/2329-891X.1000180.

[4] Nwachukwu, N. C., Orji, F. A., \& Ugbogu, O. C. (2013). Health care waste management-public health benefits, and the need for effective environmental regulatory surveillance in federal Republic of Nigeria. Current topics in public health, 2 , 149-178.

[5] Otter, J., Yezli, S. and French, G. (2011). The role played by contaminated surfaces in the transmission of nosocomial pathogens. Journal of Infections Control and Hospital Epidemiology, 32 (7): 687-699.

[6] Samuel, S. O., Kayode, O. O., Musa, O. I., Nwigwe, G. C., Aboderin, A. O., Salami, T. A. T. and Taiwo, S. S. (2010). Nosocomial infections and the challenges of control in developing countries. African Journal of Clinical and Experimental Microbiology, 11 (2): 102-110.

[7] Yagoub, S. O, Amani E. \& Agbah, L. (2010). Isolation of potential pathogenic bacteria from the air of hospital. Journal of Applied Science, 10, 1011-1014.

[8] Wen, Y., Yiting, W., Lu, L., \& Jin, H. (2019). Biofilms, the microbial protective clothing in extreme environments. International Journal of Molecular Science. 20, 3423-3428.

[9] Moges, F, Mengistu E, Yeshambel B and Walelegn W, (2014). Isolation and characterization of multiple drug resistance bacterial pathogens from waste water in hospital and non-hospital environments, Northwest Ethiopia $B M C$ Research Notes 7: 215.
[10] Rezai, M. S. Salehifar, E, Rafier, A, Langaee, T., Rafito, M Shafahi, K, \& Eslami, G, (2015) Characteristics of multidrug resistant extended- spectrum beta lactamase- producing $E$. coli among uropathogens of pediatrics in North of Iran. Biomed. Research International, 1-7.

[11] Olalekan, A. W., Asekun-Olarinmoye, E. O., Bamidele, J. O., Abodunrin, O. L. and Olowu, A. (2011). A comparative study of awareness and attitude to nosocomial infections among levels of health care workers in Southwestern Nigeria. Continental Journal of Tropical Medicine, 5 (2): 5-10.

[12] Odeyemi, A. T (2012). Antibiogram status of bacterial Isolate from air around dumpsite of Ekiti State Destitute Centre at IIokun, Ado-Ekiti, Nigeria. Journal of Microbiology Research. 2, 12-18.

[13] Jayanthi, A. (2014). Most common healthcare-associated infections: 25 bacteria, viruses causing HAIs, Becker's hospital review.

[14] Nworie, A., Ayeni, J. A., Eze, U. A. and Azi, S. O. (2012). Bacterial contamination of door handles/knobs in selected public conveniences in Abuja Metropolis, Nigeria: A public health threat. Continental Journal of Medical Research, 6 (1): $7-11$.

[15] Nejad, S. B, Syed, S. B, Ellis, B, Pittet, D. (2011). Health associated infection in Africa: a systematic review. Bulletin of the World Health Organization; 89, 757-65.

[16] White, K. M., Jimmieson, N. L., Obst, P. L, Graves, N., Barnet, A., Cockshaw, W., Paterson, D. (2015). Using a theory of planned behavior framework to explore hand hygiene beliefs at the 5 critical moments among Australian hospitalbased nurses. Biomed Centre Health Services Research, 15, 15-59. doi: 10.1186/s12913-015-0718-2.

[17] Frost M, and Sullivan K (2010). Hospital acquired infections Trends across Europe, M56E-54.

[18] Allegranzi, B., and Pittet, D. (2009). Role of Hand Hygiene in Healthcare-Associated Infection Prevention. The Journal of Hospital Infection, 73 (4): 305-315.

[19] Srinivas, P., Reddy, S. R., (2012). Screening for antibacterial principle and activity of Aerva javanica Juss. Ex Schult. Asian Pacific. Journal. Tropical. Biomedical. 2 (Supplement 2): 838845.

[20] Rajat, R., Ninama, G., Mistry, K., Parmar, R., Patel, K., and Vegad, M. (2012). Antibiotic resistance pattern in Pseudomonas species isolated at a tertiary care hospital, Ahmadabad, National Journal of Medicine. 2 (2): 156-159.

[21] Neidig, A, Yeung, A, \& Joerg, O. (2013). Type A is involved in virulence, antimicrobial resistance and biofilm formation in Pseudomonas aeruginosa. Bio MedCentral Microbiology, 77, $1-23$.

[22] Udeze, A. O., Adeyemi, A. T., Adeniji, F. O., Nwanze, J. C., Onoh, C., Okerentubga, P. O. and Okonko, I. O. (2012). Plasmid mediated ampicillin resistant bacteria isolates from University of Ilorin Health Centre. New York Science Journal, 5 (4): 56-63.

[23] Pal, R. B., Rodrigues, M. and Datta, S. (2010). Role of Pseudomonas in nosocomial infections and biological characterization of local strains. Journal of Bioscience Technology, 1 (4): 170-179. 
[24] Mlynarczyk, A, Mlynarczyk, G, Pupek, J, Bilewska, A, Kawecki, D, Luczak, M, Godowsky, J, Durlik, M, Paczek, L, Chmura, A, Rowinnski, W. (2007). Serratia marscens isolated in 2005 from clinical specimens from patients with diminished immunity. Transplantation Proceedings 39 (9): 2879-2882.

[25] Matinyi, S., Enoch, M., Akia, D. (2019). Contamination of microbial pathogens and their antimicrobial pattern in operating theatres of peri-urban eastern Uganda; a cross sectional study. BMC Infect Dis 18, 460.
[26] Anitha, J, Jayraaj I. A. (2012). Isolation and identification of bacteria from bio-hospital waste (BMW). International Journal of Pharmacy and Pharmaceutical Sciences, 4 (5): 1-3.

[27] Liberto, M. C, Matera R, Piccis, T, Lo Russo E, Colosima and E. Foca (2009). Six cases of sepsis caused by Pantoea agglomelans in a teaching hospital. New Microbial 32; 11923. 